\title{
Collaborative Online Learning: A Literature Review
}

\author{
Leoncio P. Olobia* \\ leoncio.olobia@lnu.edu.ph \\ Leyte Normal University, Paterno Street, Tacloban City 6500, Philippines
}

\begin{abstract}
Collaborative online learning engages students to become active participants in the social learning process. With the ubiquity of Information and Communication Technology (ICT), technological uptake in today's highly globalized society is a predictor for intellectual and economic growth where students and teachers play significant roles in ensuring learning continuity even in the face of disruptions.

This paper discusses theoretical justifications and empirical studies related to online learning. It provides robust knowledge in online learning.
\end{abstract}

Keywords: collaborative online learning; online learning; interactive learning

\section{Collaborative Learning Defined}

Collaborative learning is a situation in which two or more people learn or attempt to learn something together (Dillenbourg ,1990). Two or more people can be described as a pair, a small group with three to five learners, a class of 20-30 students, a community of people or a society (Dillenbourg, 1990). Another definition refers collaborative learning as an umbrella term for a variety of educational approaches involving joint intellectual effort by students, or students and teachers together (Smith \& MacGregor, 1992). In a collaborative setting, learning is an active, constructive process which depends on rich contexts from diverse learners that are inherently social (Smith \& MacGregor, 1992).

\section{Theoretical Underpinnings of Collaborative Learning}

\section{Vygotsky's Sociocultural Theory}

The concept of collaborative learning (CL) is largely rooted in Vygotsky's sociocultural theory (SCT) which views learning as inherently a social process activated through the Zone of Proximal Development (ZPD) (Vygotsky, n.d.; Dillenbourg, 1990). CL in the Vygotskian tradition aims at social interaction either among students or between students and a teacher, and essentially assists students in advancing through the Zone of Proximal Development which he defined as the distance between the actual development level as determined by independent problem solving and the level of potential development is determined through problem solving under adult guidance or in collaboration with more capable peers (Vygotsky, 1978, p.86).

\section{Anderson's Community-Centered Model of Online Learning}

The community-centred lens allows us to include the critical social component of learning in our learning designs (Anderson, 2008). Here we find Vygotsky's (2000) popular notions of "social cognition" relevant, as we consider how students can work together in an online learning context to collaboratively create new knowledge (Anderson, 2008). These ideas have been expanded in Lipman's (1991) "community of inquiry," and Etienne Wenger's (2002) ideas of "community of practice," to show how members of a learning community both support and challenge each other, leading to effective and relevant knowledge construction 
(Anderson, 2008).

\section{Moore's Interactivity}

Two forms of interaction are drawn from collaborative principle: learner-learner interaction and learnerinstructor interaction. Learner-learner interaction occurs between one learner and other learners, alone or in group settings, with or without the real-time presence of an instructor (Moore, 2014). In learner-instructor interaction, it is an interaction between the learner and the expert who prepared the subject material, or some other expert acting as instructor (Moore, 2014).

\section{Social-Constructivist Pedagogy of Distance Education}

Anderson \& Dron (2011) acknowledge the social nature of knowledge and of its creation in the minds of the individual learners. Alongside teacher's facilitative role of students' construction of meanings, social constructivism highlights the following: new knowledge as building upon foundations of previous learning, context in shaping learners' knowledge development, learning as an active rather than passive process, language and other social tools in constructing knowledge, metacognition and evaluation as a means to develop learners' capacity to assess their own learning, learning environment as learner-centered and stressing the importance of multiple perspectives, knowledge needing to be subject to social discussion, validation, and application in real world contexts (Honebele, 1996; Jonassen, 1991; Kanuka \& Anderson, 1990).

\section{Situative Perspective of Mayes \& Freitas}

This view of learning focuses on the way knowledge is distributed socially (Mayes \& Freitas, 2013). When knowledge is seen as situated in the practices of communities then the outcomes of learning involve the abilities of individuals to participate in those practices successfully (Mayes \& Freitas, 2013).

\section{Empirical Research}

A study on collaborative learning in principles of economics (Yin \& Karim, 2013), a key illustration of Anderson's Theory of Online Learning was conducted and asked the question whether collaborative online learning (COL) fostered student interest in the course, Principles of Economics in online learning. In the conduct of research, two groups were divided: 29 students using COL in online learning and the other, 27 students comprised the other group using collaborative learning in a face-to-face manner such us peer consultation, discussion of topics discussed. The COL in online learning, for this study, used online platform to engage in student collaborative learning without any face-to-face contact.

A questionnaire with 20 questions that addressed student interest in the course such as "my leader is fair in distributing work, I like to participate in this group, I encourage my friend to participate, I am willing to assist my peers," among other questions, was answered by the participants and categorized based on a 5 -point Likert scale. The study revealed that COL in online learning fostered student interest in the course, Principles of Economics rather than the face-to-face collaborative learning with COL mean (SD) at 3.867(0.252) and faceto-face- collaborative learning at $3.555(0.212)$. This outcome explained that the young generation always gets involved in online activities in their daily lives (Yin \& Kim, 2013). Furthermore, it contended that the pervasiveness of online games, the use of social media sites like Facebook, twitter and other network sites provide interactive venues where communication becomes active due to its immediacy of response and a sense of community built in the virtual platform (Yin \& Kim, 2013).

In another study on learner-centered teaching (LCT) by Ongeri (2009), students in a class on principles of economics revealed that learning was enhanced when learner-centered principles were in place (Ongeri, 2009). Using the principle of social constructivist theory, the action research used pre-/post-tests, journaling, 
observations, and interviews as methodologies which resulted in three areas of learner-centered teaching: respecting students' voice, students' voice in content and learning activities selection, students' voice in homework assignments, quizzes, and examination choices, nurturing students' development, caring for learners' selected materials' and group work assignments (Ongeri, 2009).

Some of the critical arguments against learning-centered teaching in the aforementioned research included managing the curriculum against time, overcoming the need to lecture, trusting students to complete the readings, managing the pace of learning, evaluating students (Ongeri 2009). There was also mention of 'fear' from the students when they had to take responsibility for their own learning built around uncertainty in what they would do.

In another study on collaborative learning, a comparative research that explored on PBL and Optima Design (Baker et al, 2012) wherein the former elicited teacher-designed 5-task questions in finding solutions to an economic problem in a class in principles in economics and the latter comprised 7 - task questions construed as scaffolds for more elaborate discussions on given problem sets revealed that explicit learning scaffolds meant to encourage collaborative discourse proved to be inefficient in learning. Some of the reasons for the low collaboration were time delay in feedback from the teacher and peer learners from the answers to each of the 7-task procedures. Examples of task in the Optima Design included: read the task and see if there are any difficult word, what are the main problems of the task, try to answer one or more learning goals once step 2 has been completed, elaborate on the findings of step 3 , etc.

It was also revealed that interaction between learners was high in non-task activities and low in task-activities where the latter connote procedural questions in the Optima Design. The implication of the research study was such that getting the balance between guidance and support in a collaborative learning environment is a delicate issue (Baker et al, 2012).

The foregoing research indicated an autonomous environment employing PBL and Optima Design, basically PBL only explored with more questions wherein a problematic constructivist and collaborative learning situation pervaded in a scaffold-supported discourse.

It was also argued that computer-supported collaborative learning (CSCL) environments only provided a powerful learning environment if participants actively contributed to discourse and co-constructed knowledge together. The Optima Design in the research would have been successful if task-related learning procedures were the main focus of discourse among peer learners rather than non-task activities which became the main point of interaction. Hence, it could not be understated that optimal learning in a collaborative setting rested on engaged interaction on content, learning tasks, resources and other matters related to the subject as the research indicate.

The use of hypermedia in a class in EC103 mentioned previously suggested collaborative learning through teacher-student interaction and student-student interaction in the administered computer sessions (Ping \& Lim, 2001). Tutoring role of the teacher corrected misconceptions and guided individual progress of students in mathematical reasoning with the aid of MathEcon ICT package. The application of Vygotsky's Social Construct Theory where learners take responsibility for their learning was explored extensively in studentstudent interactions in the worksheets embedded in the ICT. For instances, more advanced students would teach lesser advanced classmates in the virtual computer sessions such that shared ideas fostered optimal learning results. 


\section{Roles of Information Communication Technology}

Information Communication Technology (ICT) has paramount roles in online learning as underpinned by uses determinism and TCPK model previously mentioned. In this this section, empirical data are drawn to explore on its practical applications using ICT that is internet-based although ICT includes CD-ROMS and other noninternet based tools as well.

A study on promoting active-student learning using the World Wide Web in economics courses (Simkins, 1999) discussed the importance of the Web technology in promoting active online learning. In the journal, the discussion highlighted on the Web as a rich resource of economic news, data and information that can make economics relevant and understandable for students; The Web also makes possible new learning environments that give students with different learning styles, additional entry points into economics and multiple ways to practice economic concepts; the Web provides new opportunities for collaborative learning (Simkins, 1999). Becker (1997) listed "the need for active student involvement with classmates in the learning process", as one of the key elements in increasing students' performance and interest in further study of a subject. The Web is a natural tool for increasing student-student as well as student-instruction interaction through the use of online chat, discussion boards (Simkins, 1999). Furthemore, students using Web resources are able to practice on economic concepts, the journal expounds, through simulations, joining stock market as application of knowledge.

The important contributions of the Web on learning cannot be met without some criticisms of its use. Simkins (1999) asserted that empirical evidence of Web-based instruction for student learning in college courses is slim. Russell (1997) contended that in over 250 research reports submitted, research on the use of technology in teaching suggested that there is 'no significant difference' in the learning outcomes of students who use technology and those taught in classroom. Yet another study by Conrad (1997) that provided a survey of research evaluating the use of Web-assisted instruction (email, discussion boards, simulations, and tutorials) generally increased students' enjoyment of classes but found no solid evidence of improvement in student performance when compared with students taught using traditional methods.

The use of online economics textbook, another example of an ICT-based learning has been discussed in a research conducted by Miller (2010) which, among other things, articulated that the lack of comfort reading from the computer has slowed down the acceptance of electronic textbooks (Carlson, 2005; Nelson, 2008). Eye strain from computer screen and back and neck problems were a concern (Crawford, 2006).

Even with all the aforementioned restrictions of Web-based learning, still it cannot be denied that resurgence of ICT-based learning where the internet and the Web play critical roles has spiralled online learning. Learning will be enhanced when instructors incorporate and blend technology into their teaching pedagogy in ways that help students practice economic concepts and get them actively involved in the learning process (Simkins, 1999). The World Wide Web is an extremely multifaceted technology that provides a large-and seemingly ever-growing- set of communication and information management tools which can be harnessed for education provision (Anderson, 2008). Moreover, the Net affords interaction in many modalities (Anderson, 2008). Oliver (n.d.) mentions that ICT-based learning delivers issues such as expanding the pool of teachers - to include trainors, mentors, specialists apart from the traditional teachers in classroom, expanding the pool of students - more students are now accommodated with the flexibility provided for in ICT-based learning, cost of education - a rather ticklish issue that takes its toll on expensive technologybased education that deals with infrastructure, course development and course delivery (Oliver, n.d.). 


\section{Analysis and Conclusion}

The foregoing literature studies explored various points in student learning in online principles in economics with emphasis on collaborative and autonomous learning using ICT support. The theories of online learning by Anderson, Wedemeyer's Theory of Independent Study, Moore's types of interaction, Community of Inquiry and Wenger's Community of Practice encompassed most, if not, all of the empirical data as a result of learner-teacher, learner-learner, learner-content interactions and teacher-student tutoring as evident in autonomous and collaborative learning situations provided. Moreover, it was found out that the use of technology per se was not to be construed as a sole determining factor in learning but rather as a tool to achieve learning as articulated in the principle of uses determinism. Interactivity should not be reliant upon technological affordance alone but rather as an aid, mainly construed that technological support in ICT should provide continuity in interactivity with or without it as highlighted in the research on ITC support by Ping (2003). The same analysis accrues to the use of the Web as highlighted in the empirical findings of Simkins (1999) articulating the fact that the Web should provide learning opportunities, not learning per se as uses determinism implied. This was similar to the phrase, "the medium is not the message".

One of the findings of the author in an ICT-supported learning in economics was the rich, informative discussions on cognitive skills that can be enhanced through autonomous learning. Indeed, the study of economics, online or face-to-face requires deep analysis of facts, figures, relationships, top-bottom, bottomtop views all of which within the framework of critical thinking. What the literature has shown is that autonomous learning where students have control of their own learning greatly enhanced cognitive skills. For instance, using multimedia presentations as learning scaffolds in the empirical section of the literature aid deeper understanding of concepts along with students are interacting with the technological package through interactive graphs, simulations as evident in the example on WinEcon. This was construed as a Web 2.0 application signifying interaction of information presented.

Furthermore, social constructivist pedagogy and social construct theories as underpinnings of collaborative learning discussed previously proved that learners took an active role in their own learning. In the pursuit of achieving learning goals, real-world contexts were integrated as prior learning of theories and concepts as in the case of Optima research while some started from cognitive processing of information then later shared as implied in social constructivist learning understanding through critical evaluation of mental processes then later share within the social. Its implication rested on social intelligence that emanated from probing, participating in discourse in a socially determined setting.

In the context of autonomous learning, the research in Optima design as an application of problem-based learning revealed that there were some issues on learning inefficiency in problem-based learning. One of the reasons discussed was time lag of teacher's response to the given tasks and students' focus on non-tasks explicitly instructed by the teacher and managed by the students. The wider tasks of the Optima design implied several tasks to be considered, with each one relevant before moving on to the next making it more important for the teacher to employ learning guidance.

The connected steps in the previous paragraph highlighted associasionist perspective of learning where interconnected units of learning (tasks in the case of Optima design) formed a network of steps from easy to difficult the students had to tackle. Although it implied behavioural learning, it could not be understated that the tasks assigned to deal with Optima model were based on PBL-based constructivist learning approach, its combination exemplified cognitive-behaviourist learning approach (Anderson \& Dron, 2011). 
Finally, the study on MathEcon where surveyed students utilized ITC support in enhancing mathematical skills for deeper understanding of economics, students possessed learning control through individual pacing of multimedia presentations. This implied that autonomous learning freed the learner from constructs of the teacher resulting in a self-guided approach to the educational process.

It cannot simply be dismissed that the surveyed literature captured three presence variables of the Community Inquiry Model - cognitive presence as seen in critical thinking skills honed through autonomous learning with ITC support; teacher presence as seen in the PBL Optima Design involving 7-tasks constructed by the teacher to guide students' quest for finding solutions and in the study on EC103 that expressed teacher's presence in facilitation; community presence as articulated in collaborative learning studies signifying social presence within situated learning community. The confluence of the three variables has implicitly described a worthwhile educational experience, implicit in the sense that they were underlying themes not directly articulated in the literature mentioned as in the other theoretical underpinnings.

In conclusion, the surveyed literature studies presented a robust body of knowledge on learning that would constitute theoretical and empirical groundings for online learning. The affordances of the Net and the World Wide Web as discussed undoubtedly offered exponential learning resource alternatives for flexible learners. Moreover, possibilities for research with the use of open educational resources (OERs) such as web-based resources were to be construed as an aid to learning.

\title{
References
}

\author{
Anderson, T. (2008). Theory and Practice of Online Learning. AU Press, Athabasca University. 2nd edition. Retrieved from \\ www.aupress.ca. \\ Baumgardner, C. (2015). Cooperative Learning as a Supplement to the Economics Lecture. Pennsylvania College of Technology , Pa. \\ Mayes, T. \& de Freitas, S. ( 2013). Review of e-learning theories, frameworks and models. Coventry University. Retrieved from \\ www.curve.conventry.ac.uk. \\ Woldab, Z.E. (2013). Constructivist Didactics in Teaching Economics: A Shift in Paradigm to Be Exemplary Teacher. Academic Journal \\ of Interdisciplinary Studies. Vol.2 no. 1. Retrieved from www.researchgate.net. \\ Yin, K.Y. \& Karim, N.A. (2013). Beyond the Lecture: The Use of Collaborative Online Learning in Principles of Economics. Journal of \\ Business and Economics. Vol. 4, no. 2, pp. 157-168. Retrieved from www.academicstar.us.
}

